\title{
OPENTEL: LESSONS FROM A PANDEMIC FOR THE FUTURE OF DISTANCE EDUCATION
}

\author{
Francisco Iniesto, Victoria L. Murphy, Eileen Scanlon, Shi Min Chua, The Open University, \\ United Kingdom
}

\section{Abstract}

The move to introduce technology enhanced learning (TEL) is a trend that has been observed for decades. Following the disruption arising from Covid-19 pandemic, there has been a move to remote teaching in universities across the world. This move has put the transformation or digital revolution in the limelight in the media. TEL is of strategic importance to the conduct of teaching, learning and research in education internationally. TEL, when combined with the growing benefits of open approaches to education, leads to a potentially transformational means of learning. In this paper the authors introduce some examples of research projects from the Open University's OpenTEL research grouping. These examples highlight some of the work conducted relating to supporting students, universities, and communities using TEL during the pandemic. OpenTEL research has identified that Covid-19 has exposed the need for better institutional support for students who are facing stress and disruption in their studies; collaboration among higher educational institutions to share knowledge; better engagement in the online pivot ; and understanding of the possibilities (and limitations) for online tools to maintain existing research communities.

\section{Introduction}

The Open University (OU) was founded in 1969 and has a mission to be "open to people, places, methods and ideas". In line with this mission, there are no minimum academic qualifications needed to start a degree with the OU. Since its inception, the OU has taken learning to learners, wherever they are, using an evolving range of technologies, supporting learners from across the UK and, more recently, across the globe (Cross et al., 2019). The university has pioneered new approaches to teaching in response to the needs of its diverse set of students who are learning at a distance. The methods used are particularly interesting in relation to the teaching of Science, Technology, Engineering and Maths (STEM) subjects, where innovative methods have been used to ensure that learners 
can develop practical skills. A range of technologies are used to support learners in all subjects, ranging from broadcasting information via the $\mathrm{BBC}$, to using augmented reality to practice presentations (McFaul \& FitzGerald, 2020). Courses at the OU predominantly used a blended approach, combining online study and, where appropriate, posted materials. Prior to Covid-19 it was also the practice of the OU to support students by organising in-person and online tutorials held by hundreds of associate lecturers across the UK. During Covid-19 these tutorials were all moved to an online format.

The OpenTEL research grouping was developed to bring together university-wide interest and expertise in the research on technology enhanced learning (TEL). Coordinated by researchers from the Institute of Educational Technology (IET), we have developed a strong cross-university alliance, open to collaborations across disciplines and units, researching a broad range of topics such as inclusion, accessibility, remote learning and teaching, artificial intelligence in education, and citizen science. The strategic objective of OpenTEL research is to develop and advance understanding of how technology enhanced learning impacts teaching and learning, bringing together international understanding of this field, as well as national and local understanding. We are bringing our OU expertise together to make impacts on both approaches to, and views of, TEL research. Within the OU, OpenTEL has a unique position as a research group dedicated to the use of TEL in a manner befitting the OU's mission, in other words, exploring research-informed ways to "open up" education. Researchers have argued that TEL as a field is inherently applied and multidisciplinary (see e.g. Scanlon \& Conole, 2018). This cross-disciplinary approach (both technological and pedagogical) is increasingly needed to address complex contemporary societal challenges. In response to the complexities of effectively using TEL to support students, OpenTEL has developed new approaches, perspectives, and innovative methodologies by establishing an interdisciplinary group of researchers with backgrounds including educational technology, STEM, social science, and organisational studies. The wide diversity of group members' backgrounds allows the exploration of openness and TEL research in ways that can feed into the OU's teaching and we aim to work to ensure that researchers and practitioners can collaborate. OpenTEL provides glimpses of the future with innovative examples of evidence-based TEL.

Since we started our pan-university TEL research community (in 2016), we run regular events, Show and TEL conferences, end of project seminars, Special Interest Group (SIG) meetings, writing retreats and bidding workshops. In 2021 OpenTEL has six main research areas of activity:

1. learning in an open, connected world and at scale,

2. design and analytics in learning, 
3. language learning landscapes,

4. citizen science,

5. inclusion, and

6. professional and digital learning.

These areas represent aspects of TEL are central to our research on the future of distance education.

\section{Opening up education}

Research projects within these six areas include the following. For example, the European Massive Open Online Course (MOOC) Consortium - Labour Market (EMC-LM) which researched higher educational institutes engaging with MOOCs and microcredentials in the labour market aligned with continuing professional development (Farrow, 2020). TEL is also starting to be used to tackle global workplace issues, going beyond the sphere of formal learning, the Learning from Incidents and Implementing Action (LFIA) project examined how companies in the energy sector used TEL to learn after incidents and prevent major disasters (Murphy et al., 2018). Another example is the multiple OpenTEL projects that have led to the development of the citizen inquiry platform $n$ Quire. nQuire is a platform which was built to support personal inquiry learning among schoolchildren (Scanlon et al., 2020) but has developed into a citizen science platform for all ages.

The MAZI project team, on the other hand, combines wireless technology, low-cost hardware and open-source software to open opportunities. They created learning resources which could be accessed by anyone in the surrounding geographical area, without the need for a stable internet connection (Gaved et al., 2019). The different ways that education can be "opened up" are also demonstrated through the work of the Global OER Graduate Network $(G O-G N)$. GO-GN is a network of PhD candidates from around the world whose research projects include a focus on open education, open educational resources (OERs) and open educational practices (Weller, Farrow, \& Pitt, 2019). Finally, the Assistants to the Disclosure and Management of Information about Needs and Support (ADMINS) project created a virtual assistant to help students with accessibility needs navigate complex paperwork that can be a near-impossible task for them without such support (Iniesto, Coughlan, \& Lister, 2021). 


\section{Response to Covid-19}

Contemporary issues, such as learning at scale, open learning, and remote learning, have come to the forefront of discussion during the Covid-19 pandemic.

\section{Understanding the student experience and support needs}

OpenTEL responded to the pandemic by supporting individual group members in developing projects. For example, as a data collection tool, nQuire was used by the OU and Young Foundation to collect evidence on the impact of the pandemic on students. Working with the Mental Health Foundation and representatives from across the OU, OpenTEL is developing the concept of a Centre for Democratising Research which builds on our research approach to citizen science inquiry and nQuire. Impact is shown as this citizen science research activity has been recognised with the Guardian Award for Research impact for nQuire in 2020.

Several projects have explored the student experience and understanding the needs of students in extreme circumstances, "the impact of Covid-19 disruption" project (Aristeidou $\&$ Cross, 2021) conducted a survey (with 555 responses) during summer 2020 to investigate how OU student learning has been impacted by the Covid-19 disruption. In particular, the responses facilitated further study on undertaking specific learning, assessment, and social activities, and how students' background characteristics relate to any potential impact. The main factors affecting OU students' studies was impact on their mental health and their employment. The project indicated the need of immediate intervention strategies, including institutional and funder support (funded extensions or expedited alternatives), cultivating individual-driven coping behaviours which can be promoted by institution training programs.

With a similar objective, "the student support networks during lockdown" project used techniques from social network analysis to explore who students had been going to for help; support received from social networks are essential for helping students to maintain mental health during times of stress such as Covid-19. Early results from the analysis showed the importance of a university's communication strategy, as getting accurate information on changing policies was highlighted by participants as an important aspect of receiving support during the immediate university response. As the pandemic progressed, the project suggested that the size of students' networks did not change substantially. However, some students did reach out more frequently to their associate lecturer for academic issues, that sometimes included providing emotional support. Nevertheless, it should be emphasised that the experiences of students were very diverse, with some finding that academic studies were a welcome escape instead of an additional stress. 
Iniesto, F., Murphy, V. L., Scanlon, E., \& Chua, S. M.

OpenTEL: Lessons from a Pandemic for the Future of Distance Education

\section{Supporting other universities moving online and creating resources}

During the pandemic OU academics have informally shared expertise to other institutions and educators as they engaged in the online pivot for the first time. That involved a series of online informal drop-in sessions for sharing experience and knowledge which, in the end, become popular events (Weller, 2020) for those who needed to make the transition to online teaching quickly.

In line with opening education up beyond traditional higher educational degrees, our response also included support for the development of microcredentials and short courses, re-designing production in terms of agile methods and learning design templates as part of the OU FutureLearn Microcredentials initiative. IET has been involved in developing a FutureLearn microcredential to support anyone to discover how adults learn online - and at a distance - drawing on key theories, evaluating technologies for supporting learning, drawing on a range of experiences and research on how to design engaging and inspiring online courses successfully.

To that end, during the pandemic the OU has developed courses to promote useful support for teachers across Africa. The Pathways for learning: new approaches in higher education project, in partnership with the African Council of Distance Education, provided professional development programmes for university lecturers, instructional designers, technical and professional staff, managers, and heads of department who share responsibility for providing quality distance and online learning. It aimed at supporting educators from any discipline or professional role to better understand teaching online. Participants in the project not only gained the knowledge and skills for online teaching, but also experienced online learning themselves first-hand by engaging with well-designed materials, platforms, and experts. This learning experience has built their confidence in online teaching, as some of them reported greater confidence in pushing for change and integrating what they have learnt into their practices as part of the shift to greater online and blended approaches.

\section{Supporting ongoing community}

As discussed above, OpenTEL is a cross-university research grouping. To allow knowledge exchange between disciplines, we have hosted monthly SIG events and a two-day annual mini conference called Show \& TEL for the past five years. To continue the strong sense of community within the group, these events were quickly moved online in response to Covid-19-related restrictions. For some events, this move enabled the group to reach a wider audience and explore different ways of communication. For example, the Open and Inclusive SIG has used technology to great effect, through events such as a practical session on accessibility and TEL for visually impaired students. While these types of events were 
possible prior to the pandemic, the embrace of TEL as the norm has made potential participants more willing to engage. One highlight was a seminar on student voice attended by over 40 OU staff and students from across the UK. Students were given the opportunity to speak freely and openly about different topics. This stimulated discussion around current and emerging issues regarding accessibility at the OU. Interactive workshops, held on topics as diverse as how Covid-19 has impacted learning experiences and ethical considerations in TEL, have also been a common occurrence. The overall feedback from attendees of these events has been positive, with participants expressing their appreciation for an open and safe forum for their opinions. An advantage of these workshops has also been the opportunity to collect visual summaries of discussions as a feature of workshops, rather than needing to create and distribute summaries. Figure 1 shows a dialogue map that was used to guide and capture conversations on ethics in TEL.

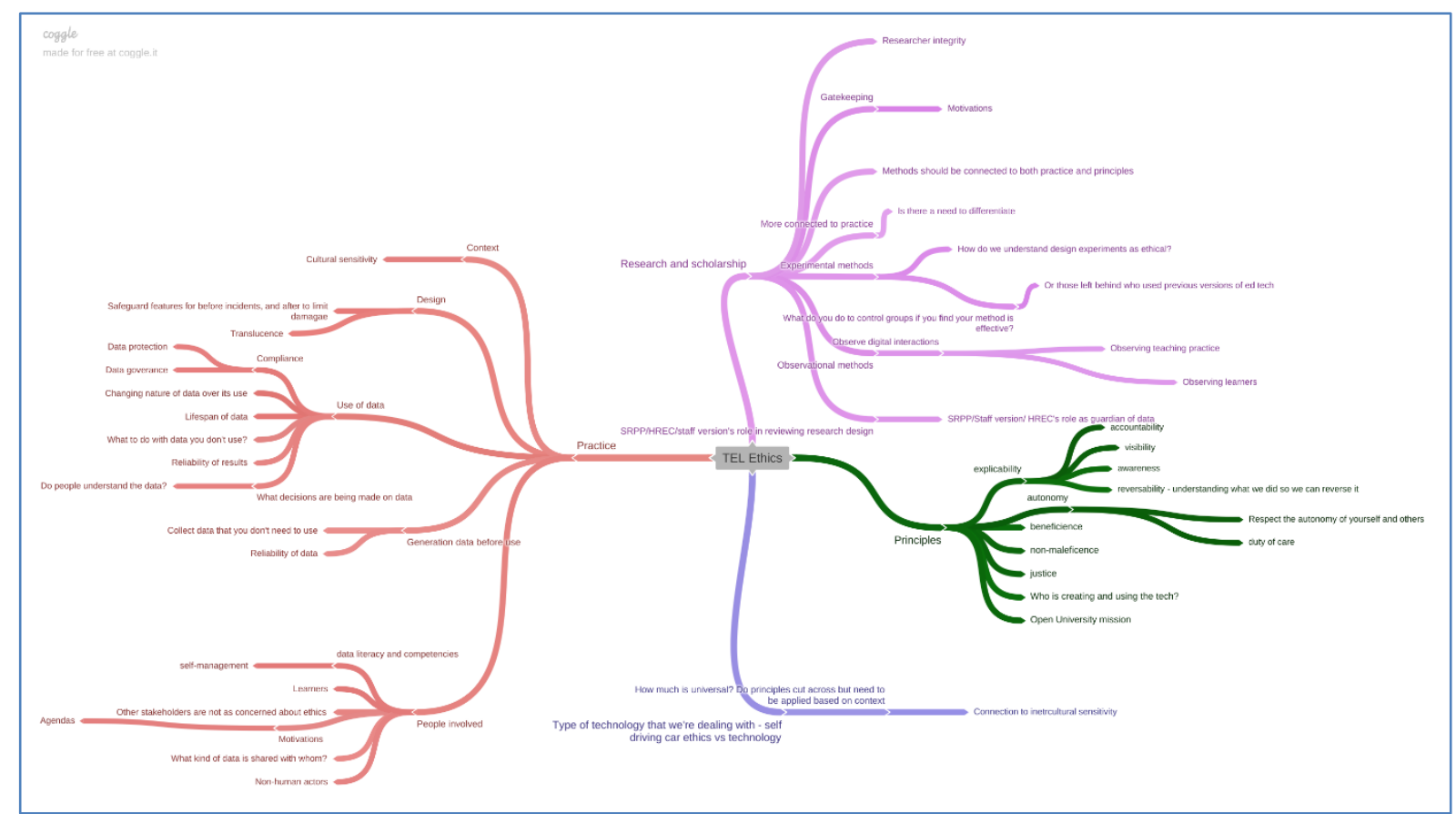

Figure 1. A dialogue map used to guide and capture conversation during an interactive workshop.

In addition to hosting our own events, OpenTEL has supported projects that have promoted the creation of TEL related communities. For example, the Computers and Learning Research Group (CALRG) moved their annual conference to an online format for the first time in 2020. The conference organisation team was funded by OpenTEL to conduct a scholarship project on the experiences of participants and organisers. Twentytwo survey responses and seven interviews allowed the project team to create a guide for others organising similar online events, which is available in full on the OpenTEL blog. A key finding was the ability of interactive asynchronous events to allow participants to take a break from listening but still have a sense of "eventedness". At the CALRG conference, for example, time for a scavenger hunt activity was scheduled during the first day, where 
participants were set challenges related to the digital platforms used (Microsoft Teams and Adobe Connect). There were also several unique advantages to an online only conference approach. For example, the digital platforms made it easy to naturally collect feedback for presenters; participants had frequently used the chat box for reflections, which could be sent to a presenter. An alternative approach was used during the doctoral consortium (part of the event), when a Google Doc was used to collect a large amount of feedback for students on their presentations. However, there were also difficulties identified with the online format. The volume of emails exchanged before the conference was much larger than it would have been if the organisers had been in the same office. Likewise, there were unexpected practical considerations, such as how to discreetly let the presenter know that the time for their presentation is running out. Perhaps the biggest surprise came when a university wide update of Adobe Connect caused the access link that the organisers had originally advertised to stop working. Planning what to do should the technology completely fail is perhaps a lesson for all. Although there were pros and cons to the digital format, one certainty was that the reduced financial and time costs allowed a greater diversity of participants to both attend and present. The CALRG conference has traditionally been a relatively small-scale event that allowed OU students to present at a friendly event with established academics. In 2020 the conference was attended by over 100 people from seven countries, including several students from other universities. The friendly nature of the conference did not change, meaning students across the world who were starting their academic journey were able to join a likeminded group in a low stakes conference. This is very much in line with opening up education.

\section{Conclusions and lessons learnt}

While the press has talked about the acceleration of the digital revolution brought about by Covid-19 (Times Higher Education, 2020), the reality is that higher education has been making increasing use of TEL for decades. Covid-19 has catalysed this, highlighting both opportunities and potential stumbling blocks for the future. The global "experiment" of most universities moving to online teaching over the course of a few months has been a baptism of fire for many in the sector, while many have capitalised on their previous experience. It remains to be seen what this accelerated shift means for the future. We have noted the impact of the increased availability of OERs and the demand for support for the move to online teaching has been filled by rapidly produced online courses. In addition, the search for ways to introduce more interactivity into remote teaching has offered opportunities for platforms such as nQuire. As universities embrace the current possibilities for supporting both formal and informal life-long learning enabled by digital technologies, there must also be caution. As the OU has long been aware, diverse students have diverse needs. TEL can tear down barriers to education, but equally can create others (Lister et al., 2020). 
In this paper we have given some examples of the ways in which we have used our developing OpenTEL research capacity to respond to the challenges of the move to digital, three key areas need to further be explored:

- Covid-19 has exposed the need to better provide institutional support for students who are facing stress and disruption in their studies.

- Experiences of collaboration among higher educational institutions to share knowledge and experiences support a better engagement in the online pivot.

- The possibilities (and limitations) for online tools to maintain existing research communities.

Our ambition is to further develop our capacity in evolving the design, content, and delivery of supported open education through research and pedagogical innovation in educational theory, methodology and practice such that we can better respond to emerging issues. We have identified equality and inclusion and learning at scale as areas of priority for us to further develop our work. We also consider that it is important to look at the ways in which we can consider research practices associated with technology enhanced learning which contribute to more sustainable choices.

\section{References}

Aristeidou, M., \& Cross, S. (2021). The impact of Covid-19 disruption on the learning activities of OU students. The Open University.

Conde Gafaro, B. (2021, February 25). OpenTEL - CALRG 2020 Evaluation Report. Retrieved from http://www.open.ac.uk/blogs/opentel/calrg-2020-evaluation-report/

Cross, S., Sharples, M., Healing, G., \& Ellis, J. (2019). Distance Learners' Use of Handheld Technologies. The International Review of Research in Open and Distributed Learning, 20(2).

eSTEeM - The OU centre for STEM pedagogy (2021). Students' support networks during lockdown. Retrieved from https://www.open.ac.uk/about/teaching-andlearning/esteem/projects/themes/other/students\%E2\%80\%99-support-networksduring-lockdown

European MOOC Consortium - EMC (2020). European MOOC Consortium Labour Market. Retrieved from https://emc.eadtu.eu/emc-lm

Farrow, R. (2020). The role of MOOCs in promoting social inclusion through employability: a rapid assessment of evidence. Italian Journal of Educational Technology, 28(3), 189-209.

FutureLearn (2021). Microcredentials. Retrieved from https://www.futurelearn.com/microcredentials/online-teaching 
Gaved, M., Calderón Lüning, E., Unteidig, A., Davies, G., \& Stevens, J. (2019). Power, Roles and Adding Value: Reflecting on the Challenges of Bridging Across Research and Action on an International Community Networking Project. Paper presented at the $17^{\text {th }}$ CIRN Conference 2019. Monash University, Italy, 6-8 November.

Global OER Graduate Network - GO-GN (2021). Retrieved from http://go-gn.net/

Guardian, The (2020, November 25). Research impact: award winner and runners-up. Retrieved from https://www.theguardian.com/education/2020/nov/25/researchimpact-award-winner-and-runners-up

Holmes, W., Porayska-Pomsta, K., Holstein, K., Sutherland, E., Baker, T., Shum, S. B., \& Koedinger, K. R. (2021). Ethics of AI in Education: Towards a Community-Wide Framework. International Journal of Artificial Intelligence in Education, 1-23.

Iniesto, F., Coughlan, T., \& Lister, K. (2021). Implementing an accessible Conversational User Interface applying feedback from University students and disability support advisors. Proceedings of the $18^{\text {th }}$ International Web for All Conference, 1-11. Taipei, Taiwan, 20-21 April. New York: Association for Computing Machinery.

Lister, K., Coughlan, T., Iniesto, F., Freear, N., \& Devine, P. (2020). Accessible Conversational User Interfaces: Considerations for Design. Proceedings of the $17^{\text {th }}$ International Web for All Conference, 1-11. Taipei, Taiwan, 20-21 April. New York: Association for Computing Machinery.

MAZI (2020). Developing a DIY networking toolkit for location-based collective awareness. Retrieved from http://www.mazizone.eu

McFaul, H., \& FitzGerald, E. (2020). A Realist Evaluation of Student use of a Virtual Reality Smartphone Application in Undergraduate Legal Education. British Journal of Educational Technology, 51(2), 572-589.

Mental Health Foundation (2021). Good mental health for all. Retrieved from https://www.mentalhealth.org.uk/

Murphy, V. L., Littlejohn, A., Rienties, B., King, S., \& Bryden, R. (2018, April). How do you know if you're learning from incidents? Paper presented at SPE International Conference and Exhibition on Health, Safety, Security, Environment, and Social Responsibility. Society of Petroleum Engineers.

nQuire (2021). Home. Retrieved from https://nquire.org.uk/

Open University, The (2020). OU supports online and mobile learning in Africa during COVID-19. Retrieved from https://www.open.ac.uk/research/news/ou-supportsonline-and-mobile-learning-africa-during-covid-19 
Scanlon, E., \& Conole, G. (2018). Interdisciplinarity in Technology Enhanced Learning: An Interview Study. Journal of Interactive Media in Education, 2018(1), 1-8.

Scanlon, E., Herodotou, C., Sharples, M., \& McLeod, K. (2020). nQuire: Citizens Acting as Scientists in Massive Open Online Learning. Proceedings of the Seventh ACM Conference on Learning@ Scale, 257-260. Virtual Event, USA, 12-14 August. New York: Association for Computing Machinery.

Times Higher Education (2020). The Future of Digital Assessment: Covid-19, Short Courses and Beyond. Retrieved from https://www.timeshighereducation.com/hub/inspera/p/future-digital-assessmentcovid-19-short-courses-and-beyond

Weller, M. (2020, March 20). Open University help for other institutions - drop in sessions. The Ed Techie [Blog post]. Retrieved from http://blog.edtechie.net/ou/openuniversity-help-for-other-institutions-drop-in-sessions/

Weller, M., Farrow, R., \& Pitt, B. (2019). GO-GN: Lessons in Building an Open Research Community. Paper presented at the Pan-Commonwealth Forum 9 (PCF). Edinburgh, 9-11 September. Burnaby: Commonwealth of Learning.

Young Foundation, The (2021). Putting people at the heart of social change. Retrieved from https://www.youngfoundation.org/

\section{Acknowledgements}

Our thanks are due to the many members of OpenTEL who have collaborated on this work over the past 5 years. 